\title{
Influence of Bitumen Emulsion Spray on Pavement Performance
}

\author{
John Richardson $^{1}$ and Connor Campbell ${ }^{2}$ \\ 1. Head of Technical Department, Colas Limited, Wallage Lane, Crawley, RH10 4NF, United Kingdom \\ 2. UK Technical Service Manager, Shell International Petroleum Company Limited, Rowlandsway House, Manchester, M22 5SB, \\ United Kingdom
}

\begin{abstract}
Bitumen emulsion sprays have an important part to play in the achievement of durable, efficient road pavement construction. Clearly, spraying of bond coats or tack coats at the interface of the bound layers should improve the likelihood of full bond and of resistance to the entry of water through the layers, both of which are needed to meet the design objectives and for the pavement to continue to function properly. BS 594987 recommends bond coats, which are typically polymer modified bitumen emulsion, as best practice and their use is prevalent for the whole range of paved areas in the UK. Recent work examines the effect of different rates of spread of bitumen emulsion sprays on interlayer adhesion and permeability, and attempts to ascertain whether there are optimum quantities to obtain the desired effects.
\end{abstract}

Key words: Bond coat, bitumen emulsion, road pavement, permeability.

\section{Introduction}

A generally common aim in asphalt pavement design and construction is sufficient durability of the structure to minimize subsequent maintenance, without entailing undue expenditure in the first instance. Various methods and techniques are available to achieve this. Best practice in the United Kingdom has been described, following a collaborative research project funded by Highways Agency (now Highways England), Quarry Products Association (now Mineral Products Association) and Refined Bitumen Association (now Eurobitume UK), as in Ref. [1]. This highlights three aspects that have a significant impact on pavement durability: control of water; limiting joints and sealing joints that have to be there; and compaction. Bitumen emulsion sprays have a part to play, to some extent, in all of these aspects.

The principal use of bitumen emulsion for bond and tack coats in asphalt pavements is to initiate or enhance adhesion between construction layers and to improve the impermeability of the layer below. Pavement design and evaluation involves an analysis of the response to loading of a fully bonded composite structure, i.e. acting as a single layer. There are techniques that are used in analytical design to assess the effect of impaired layer adhesion on performance, and predicted life can be reduced markedly, as in Ref. [2]. Sealing between the layers against water intrusion is desirable in order to avoid deterioration due to weakening at the binder to aggregate interface and to loss of stiffness in the layer. Drainage systems help to control the path of water. This assists with the expulsion of water, but it is important that the surfacing is essentially impermeable. This may mean the binder course, if the surface course accommodates water by design, e.g. porous asphalt.

Spraying of bond coats or tack coats at the interface of the bound layers in a pavement construction improves the likelihood of full bond to meet the design objectives and to resist the entry of water through the layers.

\section{Tack Coats and Bond Coats}

Traditionally, tack coats in road construction 
provide a means of initiating the bond between layers and are generally dilute, simple emulsions that are fluid enough to fill interstices in the surface. With the introduction of thin surface course systems, bond coats, that are more viscous with cohesive binders, provide a thicker film to ensure interlayer bond and impermeability. They are typically polymer modified bitumen emulsion, with a binder having a minimum peak cohesion by pendulum of $1.0 \mathrm{~J} / \mathrm{cm}^{2}$. BS 594987 [3] recommends bond coats as best practice and their use is prevalent for the whole range of paved areas. However, the fluid nature of tack coats make them particularly suitable for the treatment of dusty surfaces that are difficult to clean, and they remain useful for smaller and more lightly trafficked areas.

BS 594987 specifies minimum target rates of spread of residual binder with a permitted deviation of $20 \%$. This should ensure that residual binder from bond coat is never less than about $0.15 \mathrm{~kg} / \mathrm{m}^{2}$. Higher rates are required for planed surfaces so that it should not be less than about $0.3 \mathrm{~kg} / \mathrm{m}^{2}$, in this case.

It is reasonable to assume that greater amounts of binder in the pavement will provide better sealing and resistance to water. Between layers, though, thicker films of certain binders could lead to problems of pick up on tyres at the time of construction, especially under the time pressure of night closure and subsequent opening to traffic, or to possible slippage under traffic in service. Most binders will benefit from having time to stabilise in situ before they are open to construction traffic. Rapid breaking of an emulsion may also impair their ability to penetrate the surface properly.

Recent work examines the effect of different rates of spread of bitumen emulsion on interlayer adhesion and permeability, and attempts to ascertain whether there are optimum quantities to obtain the desired effects.

\section{Interlayer Adhesion}

\subsection{Adhesion Tests}

There are two main methods of test for pavement interlayer adhesion, both of which assess the resistance to a type of horizontal shear stress, as in Ref. [4]. The shear bond test is a laboratory test that subjects cylindrical specimens to direct shear loading at constant shear rate. The torque bond test uses cores that are tested in-situ or extracted from the pavement and tested in the laboratory. A steel plate is glued to the surface of the core and rotational horizontal force applied.

\subsection{Asphalt to Concrete}

The first study examines the bond of an asphalt layer of $10 \mathrm{~mm}$ SMA surface course to a new C40 concrete base surface, including different types of curing treatment. Achievement of good bond of asphalt layers to concrete is considered more difficult than to another asphalt. Application of bond coat between layers gave a residual binder content of $0.35 \mathrm{~kg} / \mathrm{m}^{2}$.

Table 1 gives the average results of test. The conclusion from this is that the type of curing compound on the concrete resulted in very similar bonding strength for both types of test. Guidelines for thin surfacing systems on highways suggest that $\geq 400$ $\mathrm{kPa}$ is acceptable for the torque bond strength at $20^{\circ} \mathrm{C}$, as in [5], and all of the results are consistent with this recommendation.

Further work considered the effect of different types of bitumen emulsion sprayed between layers on the bond strength. In this case, there was no curing compound used for the concrete (covered with polythene for curing).

Table 2 gives the average results of test. The residual binder content of the spray remained at $0.35 \mathrm{~kg} / \mathrm{m}^{2}$. However, the type of emulsion affected the bond strength, so that bitumen modification improves the bond. The use of the more fluid emulsion of $50 \%$ binder content improves the bond further.

The study extended to examining the effect of binder spread rate on interface bonding. Figure 1 gives the plotted results for each of the three emulsion sprays. This shows that the bond strength of the modified binders reduces at high rates of spread, possibly due to 
Table 1 Results of interlayer bonding for concrete base and SMA surface course with bond coat.

\begin{tabular}{llll}
\hline Test & \multicolumn{3}{c}{ Concrete curing type } \\
\cline { 2 - 4 } & No curing compound & Bitumen emulsion tack coat & Wax based curing compound \\
\hline Mean shear strength @ $20^{\circ} \mathrm{C}, \mathrm{MPa}$ & 0.770 & 0.691 & 0.704 \\
Mean torque bond strength @ $20^{\circ} \mathrm{C}, \mathrm{kPa}$ & 426 & 444 & 433 \\
\hline
\end{tabular}

Table 2 Results of interlayer bonding for concrete base and SMA surface course with different types of bitumen emulsion spray.

\begin{tabular}{llll}
\hline Test & \multicolumn{2}{c}{ Type of bitumen emulsion spray } \\
\cline { 2 - 3 } & $70 \%$ binder content, unmodified & $65 \%$ binder content, modified & $50 \%$ binder content, modified \\
\hline Mean shear strength $@ 20^{\circ} \mathrm{C}, \mathrm{MPa}$ & 0.96 & 1.16 & 1.50 \\
\hline
\end{tabular}

slip of an excess amount. To achieve the same bond strength, the unmodified binder requires a significantly higher rate of spread, over the practicable range of application.

\subsection{Asphalt to Asphalt}

A second study examines the bond of an asphalt layer of $10 \mathrm{~mm}$ SMA surface course to $20 \mathrm{~mm}$ dense asphalt concrete binder course, with different rates of spread of two types of bitumen emulsion spray. Figure 2 gives the plotted results for each emulsion spray. This shows again that the bond strength of the modified binder reduces at higher rates of spread, possibly due to slip of an excess amount. The bond strength is significantly higher, as expected, than that obtained with a concrete substrate and it appears that the optimum rate of spread should be lower. Over the practicable range of application, the unmodified binder achieves generally lower bond strength.

The absolute values of the test will be interface dependent, but the results here should help to give a reasonable explanation of behaviour of the types of systems examined.

\section{Permeability}

Figure 3 shows the test device for measuring water permeability. It allows the test to be carried out under different pressures (0 to 3 bars). This has the advantage of reducing the test time, which is useful in the case of very low permeability asphalt.

The equation used for the calculation of permeability
(K) in $\mathrm{m} / \mathrm{s}^{-1}$ is as follows:

$$
K=\frac{Q \cdot L}{A \cdot(h 2-h 1)}
$$

Where:

$\mathrm{Q}$ is water flow $\left(\mathrm{m}^{3} \cdot \mathrm{s}^{-1}\right)$,

$\mathrm{L}$ is thickness of the specimen (m),

$A$ is area of the sample $\left(\mathrm{m}^{2}\right)$, and

(h2 - h1) is water column (m)

$150 \mathrm{~mm}$ diameter specimens of $20 \mathrm{~mm}$ asphalt concrete are compacted by gyratory device to provide sufficient air voids so that they are interconnected (target 7-8\%). The specimen diameter is reduced by coring to $\sim 124 \mathrm{~mm}$. Weighing of the specimen with an application of broken emulsion on the surface provides a means of quantifying the residual binder. Sealing of the space between the specimen and the test mould is ensured by filling with bitumen around its entire thickness.

This study examines the effect of rate of spread of two different types of bitumen emulsion spray on the permeability to water of the asphalt specimen. Figure 4 gives the plotted results for each emulsion spray.

As expected, the permeability of the asphalt layer decreases with increasing amount of residual binder. It appears that the more fluid bituminous spray with modified binder is more effective at the lower rates of application than is the more viscous spray with unmodified binder. At higher rates, it is not possible to differentiate between them. However, due to the scatter of results, more data are needed to support the conclusions. 


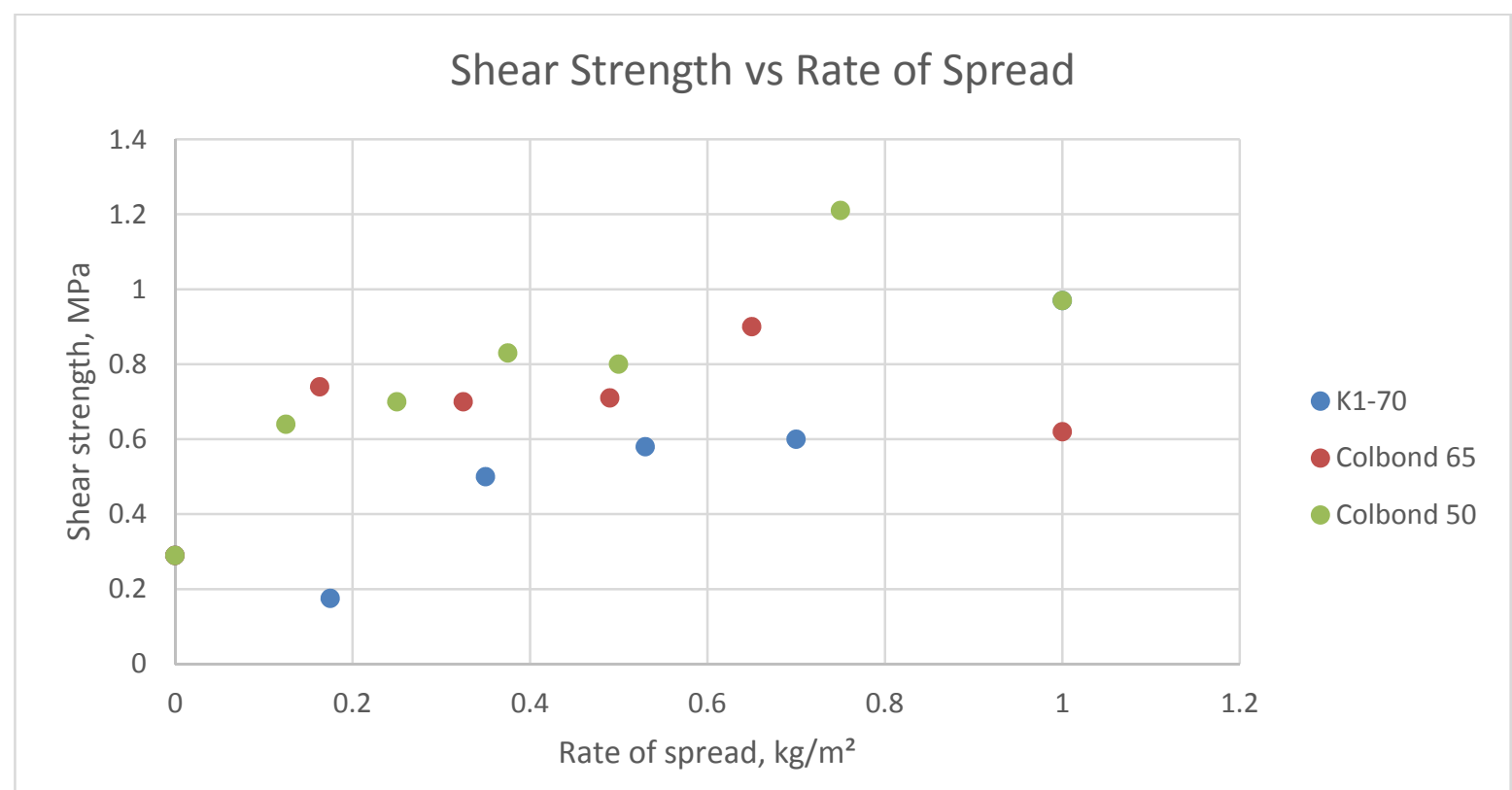

Fig. 1 Effect of rate of spread of residual binder of bitumen emulsion sprays on shear strength of asphalt-concrete interface.

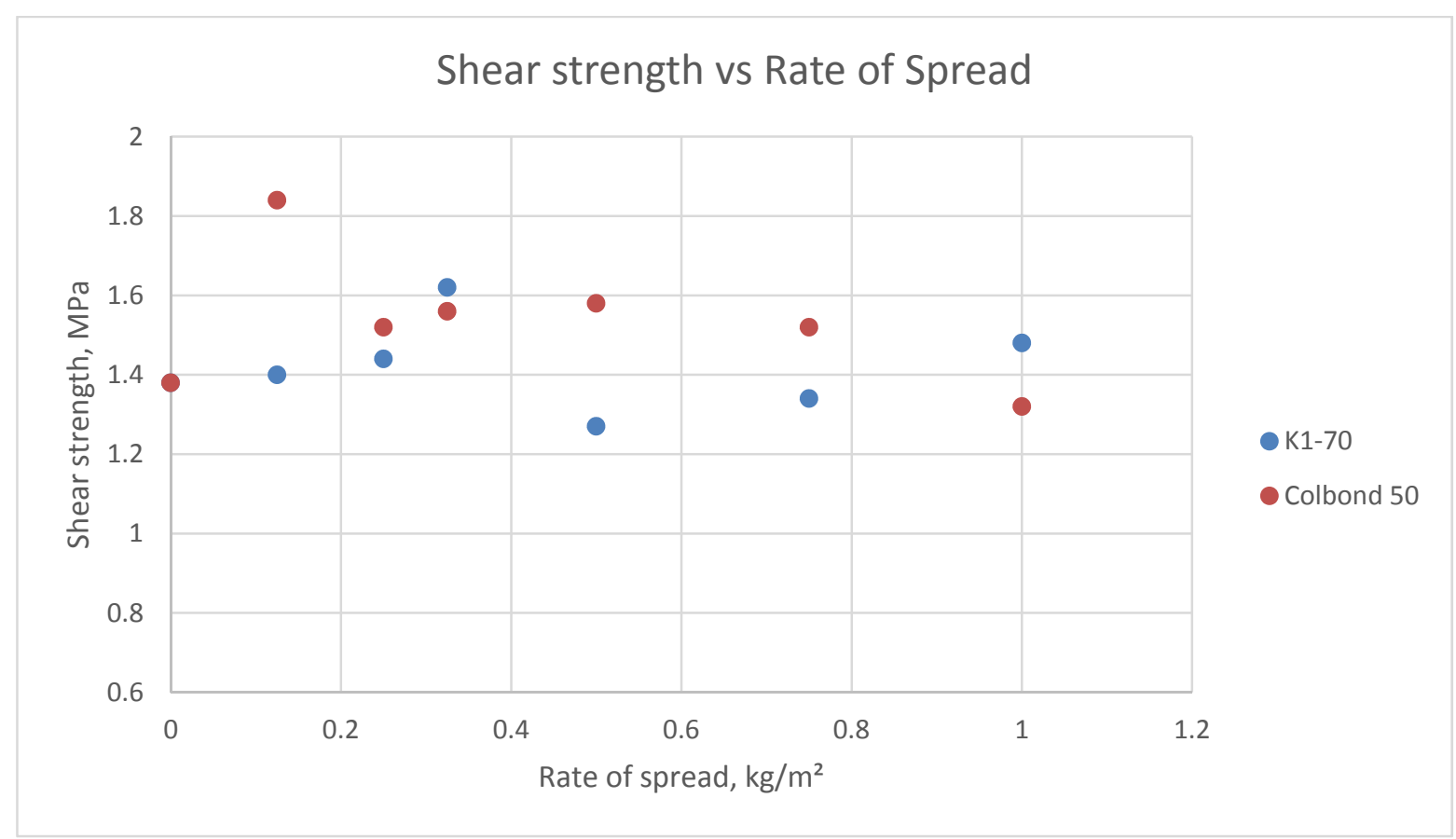

Fig. 2 Effect of rate of spread of residual binder of bitumen emulsion sprays on shear strength of asphalt-asphalt interface. 


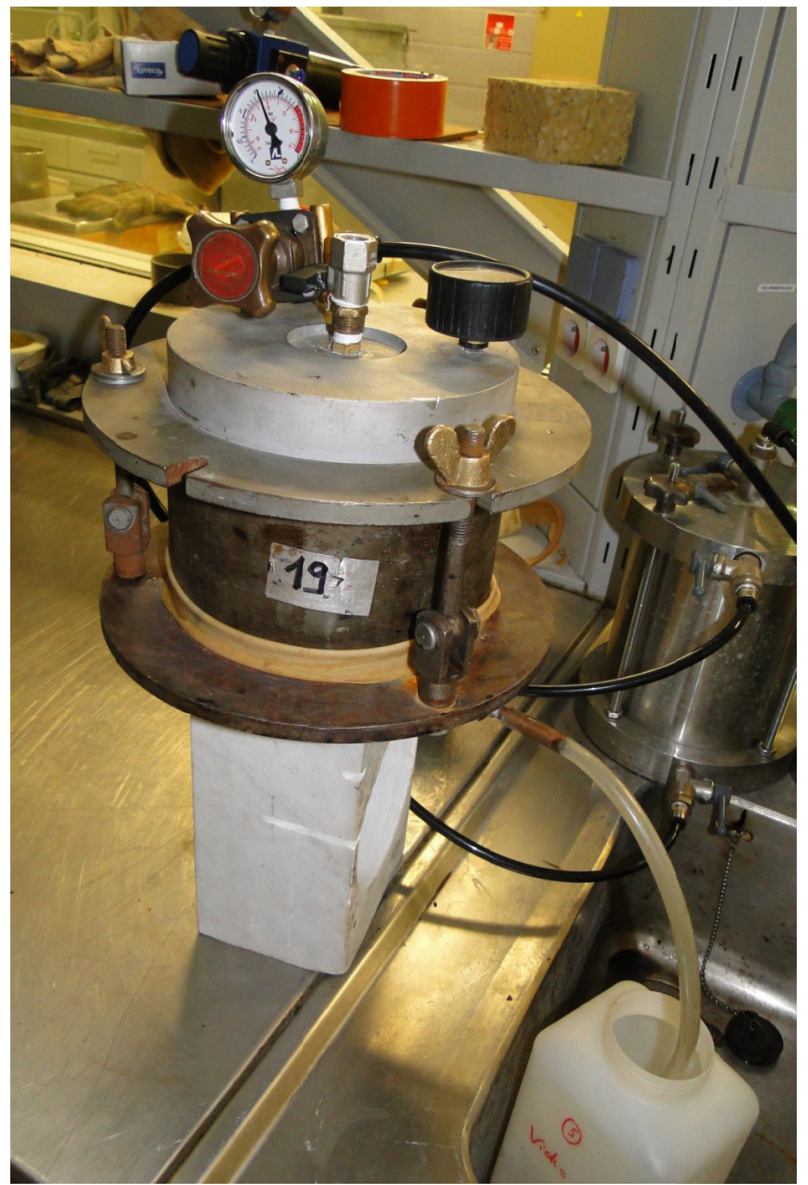

Fig. 3 Test equipment for measuring permeability of specimen.

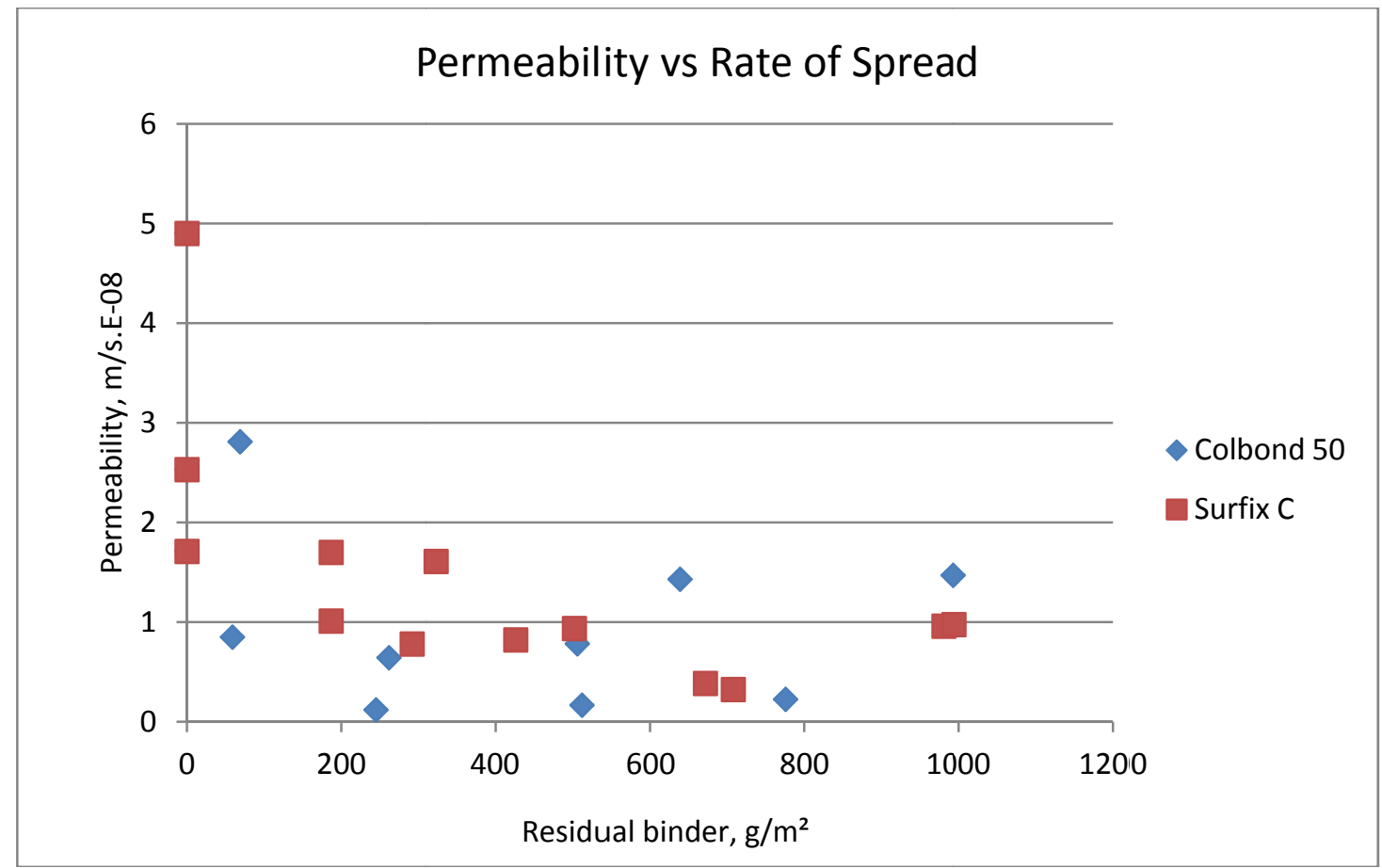

Fig. 4 Effect of rate of spread of residual binder of bitumen emulsion sprays on vertical permeability. 


\section{Conclusions}

The right type of bituminous spray at the interface can ensure sufficient bond of asphalt to concrete, irrespective of the type of curing compound.

The more fluid types of bituminous spray with modified binder enhance interlayer bond.

The bond strength between layers with modified binder reduces at the higher rates of application, possibly due to slip of an excess amount.

Over the practicable range of application, the bituminous spray with unmodified binder achieves generally lower bond strength.

The bond between asphalt layers is significantly greater than that obtained with a concrete substrate and it appears that the optimum rate of spread of bituminous spray for the former case should be lower.

Permeability of an asphalt layer decreases with increasing amount of bituminous spray on its surface.

The data scatter is such that there is a low level of confidence, but, at the lower rates of application, it appears that the more fluid bituminous spray with modified binder is more effective at resisting penetration of water into an asphalt layer than is the more viscous spray with unmodified binder.

\section{Acknowledgments}

The authors are indebted to Bernard Yvinec at the Colas Campus for Science and Techniques for his assistance with the permeability studies.

\section{References}

[1] Nicholls, J. C., McHale, M. J., and Griffiths, R. D. 2008. "Best Practice Guide for Durability of Asphalt Pavements." Road Note 42, Transport Research Laboratory, Wokingham.

[2] Richardson, J. 2006. "The Importance of Bond Coats and Tack Coats.” Asphalt Professional, No. 21, July 2006, Institute of Asphalt Technology.

[3] British Standards Institution. 2017. BS 594987: 2015+A1. Asphalt for Roads and Other Paved Areas - Specification for Transport, Laying, Compaction and Product Type Testing Protocols. British Standards Institution, London.

[4] CEN. 2013. prEN 12697-48: 2013. Bituminous Mixtures - Test Methods for Hot Mix Asphalt - Part 48: Inter-Layer Bond Strength. CEN, Brussels.

[5] BBA. 2013. "Interim Guideline Document for the Assessment and Certification of Thin Surfacing Systems for Highways.” June 2013, British Board of Agrément. 